\title{
Occupant requirements in residential buildings - an empirical study and a theoretical model
}

\author{
Conrad Voelker ${ }^{\mathrm{a}}$, Julia Beckmann ${ }^{\mathrm{b}}$, Sandra Koehlmann ${ }^{\mathrm{a}}$, Oliver Kornadt ${ }^{\mathrm{a}}$ \\ a Department of Building Physics, Coudraystrasse 11a, Bauhaus-Universität Weimar, 99423 Weimar, Germany \\ ${ }^{b}$ Marketing Center Münster, Am Stadtgraben 13-15, Westfälische Wilhelms-Universität Münster, 48143 Münster, Germany
}

(Published online: 29 Jan 2013)

\section{Copyright Notice}

Copyright 2013 Taylor \& Francis. This article may be downloaded for personal use only. Any other use requires prior permission of the author and Taylor \& Francis.

The following article appeared in the journal Advances in Building Energy Research 7 (1), 35-50 (2013) and may be found at http://dx.doi.org/10.1080/17512549.2012.749808.

\begin{abstract}
Occupant needs with regard to residential buildings are not well known due to a lack of representative scientific studies. To improve the lack of data, a large scale study was carried out using a Post Occupancy Evaluation of 1,416 building occupants. Several criteria describing the needs of occupants were evaluated with regard to their subjective level of relevance. Additionally, we investigated the degree to which deficiencies subjectively exist, and the degree to which occupants were able to accept them. From the data obtained, a hierarchy of criteria was created. It was found that building occupants ranked the physiological needs of air quality and thermal comfort the highest. Health hazards such as mould and contaminated building materials were unacceptable for occupants, while other deficiencies were more likely to be tolerated. Occupant satisfaction was also investigated. We found that most occupants can be classified as satisfied, although some differences do exist between different populations. To explain the relationship between the constructs of what we call relevance, acceptance, deficiency and satisfaction, we then created an explanatory model. Using correlation and regression analysis, the validity of the model was then confirmed by applying the collected data. The results of the study are both relevant in shaping further research and in providing guidance on how to maximize tenant satisfaction in real estate management.
\end{abstract}




\section{Introduction}

Because people spend most of their time in buildings, it is important to investigate the requirements and needs of building occupants. Few studies have been conducted that explore the needs of occupants as well as the way that occupants weight those needs. One of the most comprehensive surveys to date investigated more than 50,000 occupants in 351 American office buildings (Frontczak et al., 2012b) using a web-based questionnaire (Zagreus et al., 2004). In the survey, 15 parameters defining indoor environmental quality (IEQ) were investigated with regard to their impact on overall occupant satisfaction. Finally, the criteria were classified as either "basic" factors, such as temperature, or "proportional" factors, such as air quality, which had a linear impact on satisfaction (Kim et al., 2012).

In another study, 14 large office buildings in Germany were evaluated (Bischof et al., 2003). Approximately 4,600 occupants were asked about their conditions and needs. Some of the occupants' workplace conditions were also measured. In a secondary analysis, ventilation, temperature, humidity and air movement were ranked as very or extremely important (Hellwig, 2005).

Gossauer (2008) analysed occupant satisfaction with regard to thermal comfort in a number of German office buildings. Similar studies were undertaken by Wagner et al. (2007) and Wagner et al. (2008). When comparing the results with measurements of the indoor climate, a correlation of numerous climatic, psychological and other criteria could be shown. As a result, Schakib-Ekbatan et al. (2010) developed the concept of an overall building index of six comfort parameters. .

In other studies of office buildings in China (Cao et al., 2012) and North America (Choi et al., 2012; Haghighat et al., 1999), occupant satisfaction was found to correlate with measurements of several IEQ parameters. Similar approaches investigated several IEQ parameters in terms of their acceptability to occupants (Wong et al., 2007) and in terms of the influence on occupant health (Muhic et al., 2004). The focus of yet another study measured the impact of IEQ maintenance management on occupant satisfaction (Kwon et al., 2011).

The influence of building standards on occupant satisfaction has also been investigated. While Zhang et al. (2011) found a significant influence, Paul et al. (2008) did not. Hummelgaard et al. (2007) were unable to find significant differences in satisfaction between occupants of mechanically and naturally ventilated office buildings. Humphreys (2005) investigated how highly building occupants in various countries rated different factors impacting comfort. The results varied between the countries. For example, air movement was considered to be important by French occupants, but unimportant by Greek ones. These differences might be due to the differences in natural climate in the places studied.

All the surveys listed above were exclusively conducted among office occupants. However, the needs of occupants in residential buildings are significantly different, as demonstrated by Prechtl et al's (2007) qualitative comparison of 15 housing occupants and 10 office workers. Unfortunately, very few existing studies deal with residential occupants and their needs. One German example examined 1,200 tenants regarding their satisfaction with their housing situation. The survey used a weighted questionnaire that focused on housing, building and site characteristics (Kühn, 2008). Physiological parameters were thus somewhat neglected and issues such as efficiency and design were pushed into the foreground.

Lai et al. (2009a) measured IEQ in 32 residential apartments in Hong Kong. The occupants were also asked about the IEQ acceptance. It was found that thermal and aural parameters were the most important for an overall acceptance of IEQ. In a similar study of high-rise residential building residents, thermal comfort was found to be the most important parameter, ahead of air quality and noise (Lai et al., 2009b). A questionnaire survey was also conducted of residential occupants in Denmark (Frontczak et al., 2012a). The respondents considered air quality, as well as visual, acoustic and thermal parameters to be the most important factors for comfort.

In summary, the very few existing studies dealing with occupant needs and the different weightings of those needs have been mainly focused on office buildings. Often, the focus has been on a few individual parameters such as thermal comfort. Representative studies dealing with occupant requirements, especially in residential buildings are rare. Furthermore, not much is known about the interactions of criteria with one other. The present study aims to improve these deficits in the existing empirical literature.

\section{Data collection and sample analysis}

Data was collected using a Post Occupancy Evaluation (POE). In this kind of evaluation, formal, aesthetic and structural aspects are in the background compared with actual occupant needs (Meir et al., 2009). In the wording of the questionnaire, an emphasis was given to general intelligibility over technical language. An online survey (CAPI-method) was conducted in order to appeal to target groups throughout Germany. The Sozioland-Panel made by Globalpark AG was used to reach 1,136 respondents online. Another 280 respondents were reached via post, in collaboration with the municipal housing administration Weimarer Wohnstätte (Bergelt et al., 2010).

This study analyses a sample of 1,416 respondents, of which $54 \%$ were female. The sample was distributed across all ages, as shown in Figure 1a. The proportion of single people in the sample $(43 \%)$ differed slightly from the proportion found in the general German population, which is $27 \%$ (German Federal Statistical Office, 2009a). The distribution of housing types matches the real-world situation (Figure 1b). The distribution of occupants by occupation also quite well matches the national norm (Figure 1c). In this figure, unemployed and employed people belong to a single category called 'employable people' which is a definition of the German Federal Statistical Office. The sample shows a slightly higher proportion of tenants versus owners than found in the general German population (Figure 1d). 
The majority of the respondents live in the German federal states of Thuringia, North Rhine-Westphalia, Bavaria and Baden-Wuerttemberg, although all federal states are represented in the survey. As the following analyses refer to correlations and causality analyses, and do not put descriptive results in the foreground, the meaning of regional origin fades into the background. Overall, the distribution varies only slightly from the actual situation in Germany, and thus the sample is regarded as representative, with minor reservations.

(a)

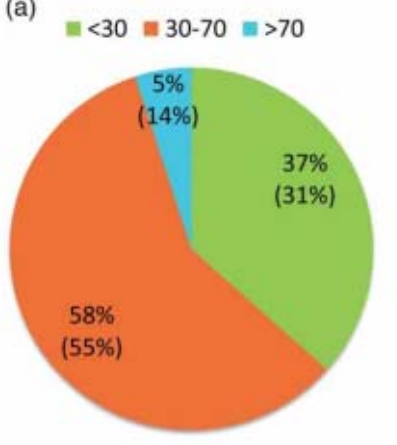

(c) $=$ Student $\quad$ Employable

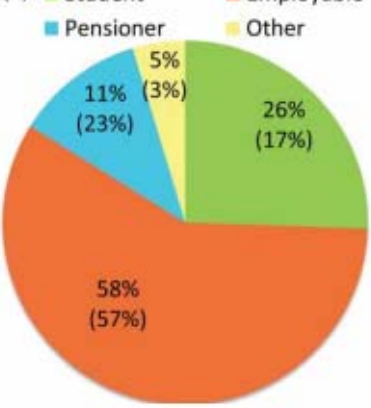

Fig. 1. Sample analysis: (a) age, (b) housing situation, (c) occupation and (d) ownership situation. Values in brackets show the base population according to German Federal Statistical Office $(2008,2009 \mathrm{~b})$

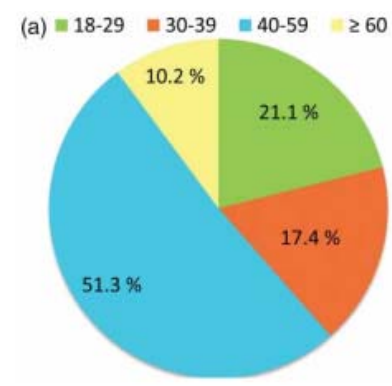

(b)

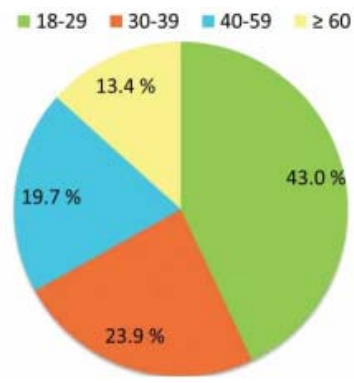

Fig. 2. Comparison of age diversity: (a) owners and (b) tenants.
However, the variables are not independent from each other. The age diversity among owners and tenants (Figure 2) serves as an example showing the differences in the age distribution between these two groups. Whereas nearly the half of all owners are between 40 und 59 years old the majority of tenants are between 18 and 29. The average age of owners is 44 years $(\sigma=14)$ whereas the tenants are on average only 38 $(\sigma=16)$. These differences give reasons to expect that the two groups, when evaluating their living situations, would put emphasis about what was important in different places. Additionally, it is unclear whether the differences in result are the results of the age, the ownership patterns or other factors.

\section{Results}

\subsection{Relevance of criteria}

In a preliminary study of occupant needs, we identified 11 criteria that were indicative of user-oriented buildings (Münster, 2009; Voelker et al., 2011). The aim of the study was the development of a clear and manageable compilation of these criteria. This study uses these same criteria, and the list thus does not claim to be exhaustive. In order to easily compare the results with those of other studies, the list of criteria (see Figure 8) was adjusted with those found in existing building assessment tools.

One of the key questions of the questionnaire dealt with the relevance of a list of criteria from the perspective of the occupants. We asked "How important are the following criteria for you in your place of residence?" For the assessment, a 5-pole Likert-Scale was used, in which 1 indicates very important and 5 very unimportant (see screenshot in Figure 3). With the help of descriptive analyses, an overview of participant preferences is given in Figure 4. The interpretations are made irrespective of target group.

Using the subjective relevance that respondents gave to individual criteria, we derived a ranking for the total sample. The ranking is based on the average, whereby the precise order of closely spaced criteria could be verified by another question asking the respondents to rank the criteria directly. In this figure, the averages are shown as points and the standard deviation is shown as a line. The results clearly show the physiological needs of air quality and thermal comfort are the most essential. This finding supports Maslow's theory of a hierarchy of needs, which says that physiological needs must be fulfilled before other higher-order needs, such as belonging needs and self-actualization needs can be met. These criteria are immediately followed by energy use, whose relevance has risen during the last years because of increasing fossil fuels prices. The next most significant criterion is acoustic comfort, with visual comfort coming in fifth place. Criteria such as vibration protection and accessibility bring up the rear. It is also striking that the standard deviation rises with decreasing relevance. 


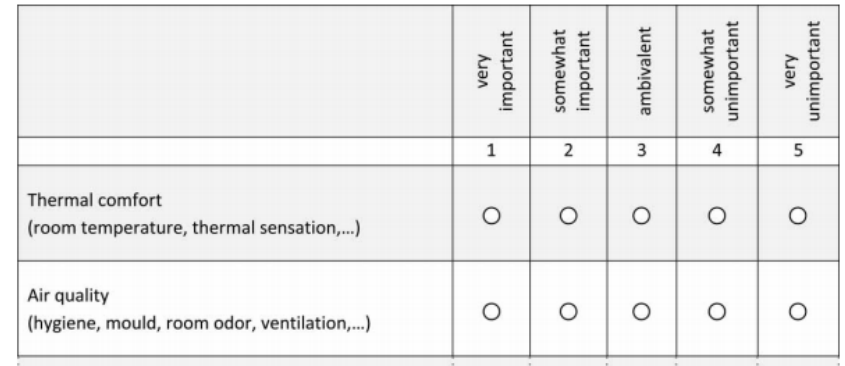

Fig. 3. Extract from the questionnaire.

\subsection{Acceptance of deficiencies}

Besides investigating the subjective relevance of criteria in housing stock, we also investigated the degree to which people found particular deficiencies in their accommodations to be tolerable. To probe this question, it was asked: "Which deficiencies can you accept in your living environment". Again, a 5-pole Likert-Scale was used, in which 1 indicates that a deficiency was found to be acceptable and 5

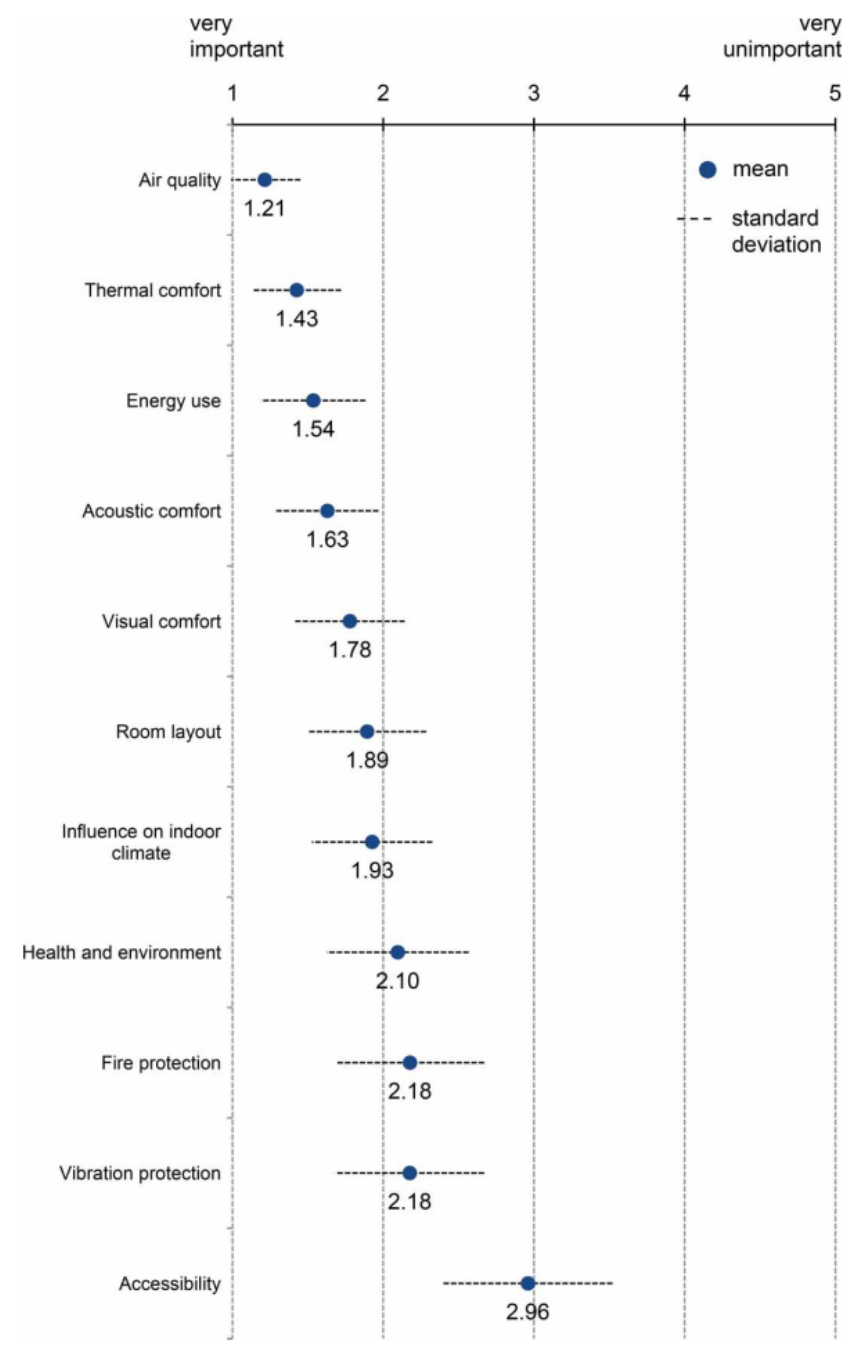

Fig. 4. Ranking of criteria in terms of relevance. was not acceptable. As shown in Figure 5, health-harming inadequacies such as mould and contaminated materials were universally deemed unacceptable, which becomes visible because of the low standard deviation. After the pollutants, high heating costs were next on the list. Compared to the first two criteria, this factor showed the highest deviation. Finally, barriers, limited escape routes and solar glare were found to be relatively widely accepted.

\subsection{Perceived deficiencies}

We also studied the degree to which people felt that deficiencies in their accommodations constituted an impairment to their lives, asking the question, "How much do you feel impaired by this factor in your personal living environment?" This assessment also employed a 5-pole LikertScale, with 1 indicating very strongly and 5 indicating not at all. The negative factors that respondents ranked most strongly were high energy costs, noise, problems with thermal comfort (draught, cold walls, etc.) and too small storage spaces. Opinions on these vary significantly, as shown by a large standard deviation in the results. This variation could be explained by differences among target groups.

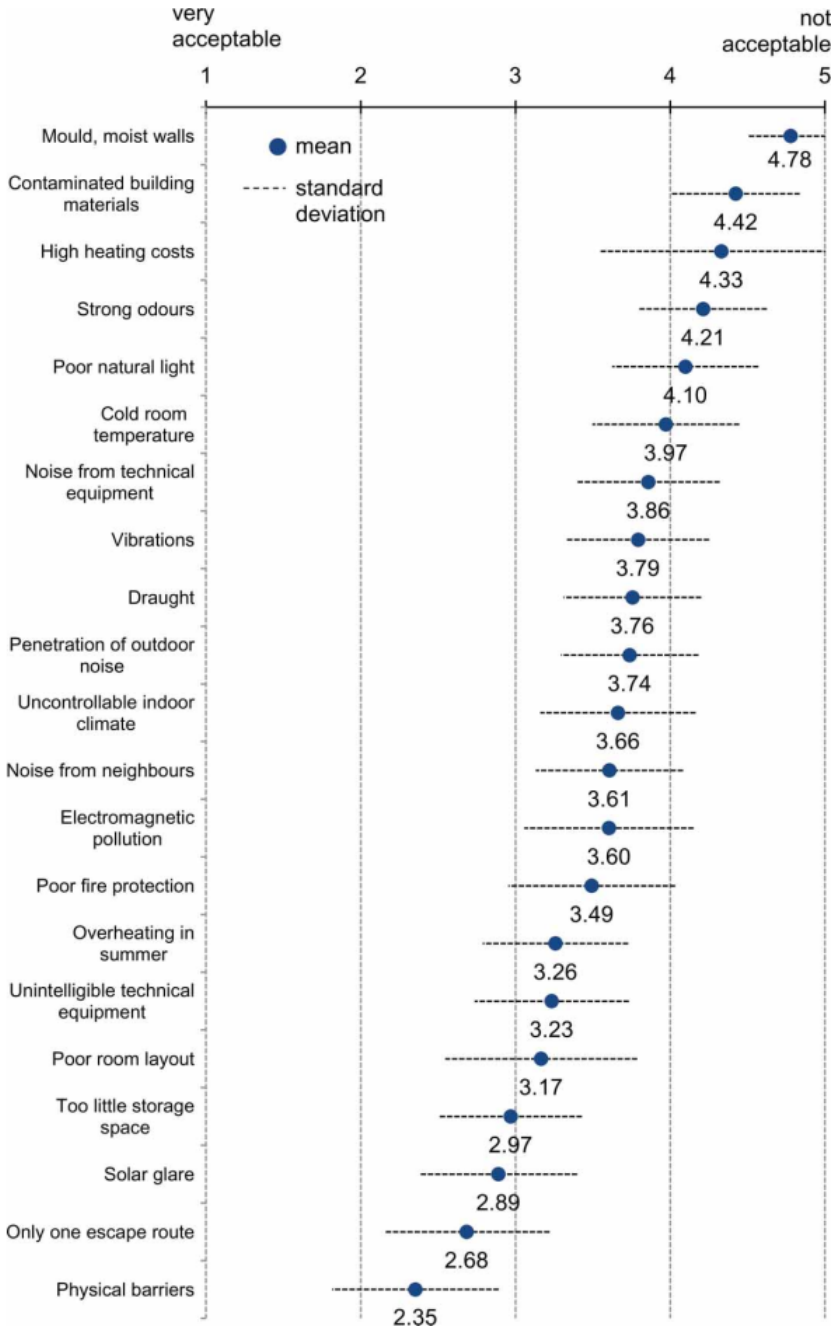

Fig. 5. Ranking of the acceptance of deficiencies. 
Summer overheating, poor fire protection and an uncontrollable indoor climate occupy the middle positions in the ranking.

All in all, comparatively high values should be noted, meaning that the average participant feels just only a little impaired by deficiencies. Only $25 \%$ of occupants see high energy costs as a strong or very strong deficiency. Similarly, $23 \%$ saw noise as a strong deficiency. $19 \%$ found thermal comfort, which includes both draught and cold walls, to be a strong or very strong deficiency. Just as physical barriers were seen to have the lowest relevance and the highest acceptance, here too, they brought up the rear, indicating that this criterion does not seem to be regarded as a deficiency for residential occupants.

\subsection{Occupant satisfaction}

The fact that deficiencies were in general perceived to be minor is reflected in our findings with regard to occupant satisfaction. Nearly a quarter of occupants considered themselves to be very satisfied with their current living conditions, with $70 \%$ identifying themselves as either very satisfied or satisfied. In comparison, only $9 \%$ reported being unsatisfied or very unsatisfied. These results are comparable with those of Kühn (2008).

Figure 7 shows the degree of occupant satisfaction that was found in the different target groups interviewed. Generally, all target groups could on the whole be classified as satisfied. Satisfaction also generally showed to increase with age, and males were found to be slightly more satisfied with their dwellings than females, confirming the finding of Choi et al. (2010).

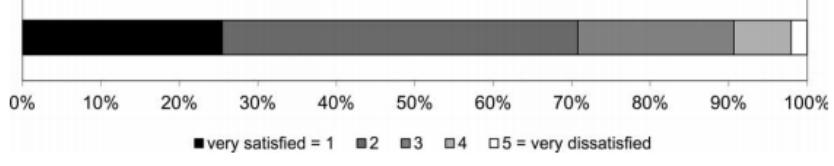

Fig. 6. Occupant satisfaction.

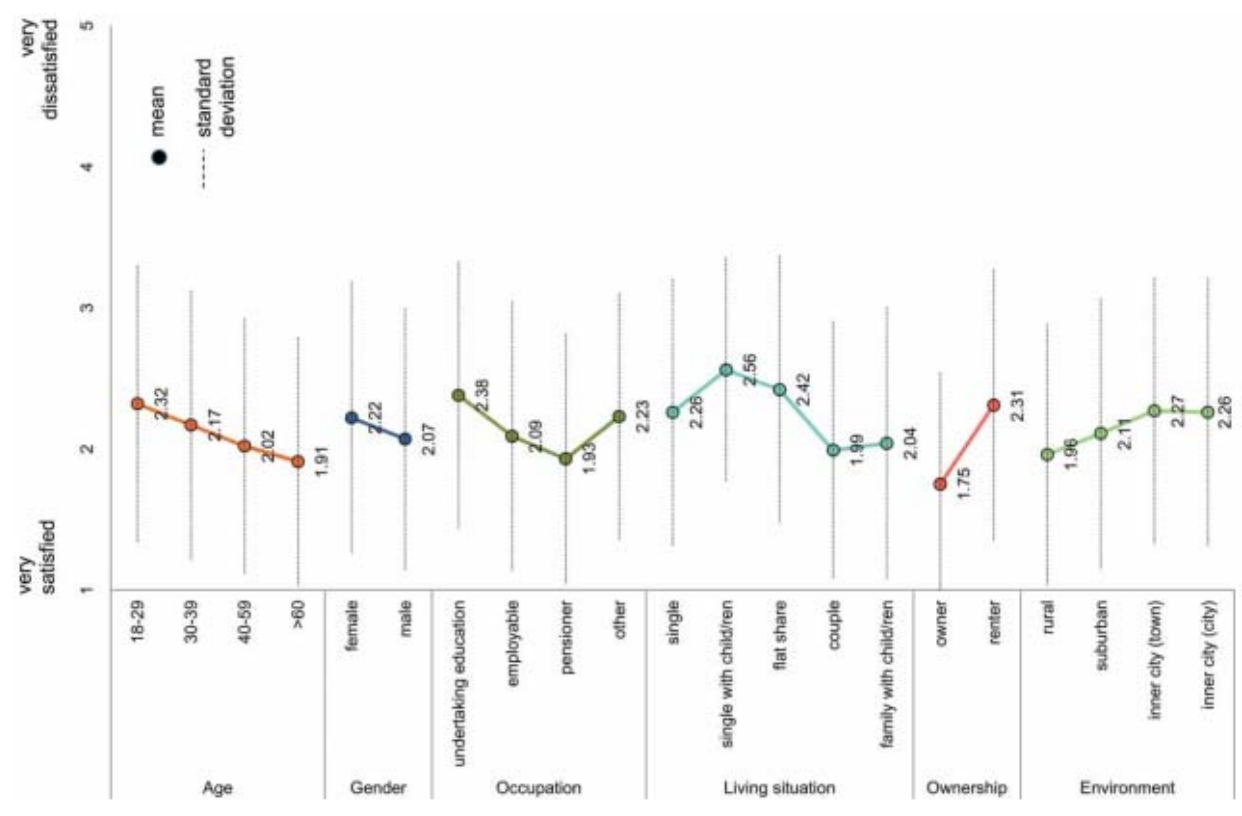

Fig. 7. Mean occupant satisfaction of different target groups.

The level of satisfaction of different occupation groups also shows differences. People still undertaking their education, including all groups from pupils up through university students were on the whole less satisfied with their living conditions than employable people or pensioners. However, they also tend to be younger. Thus, it is not clear whether age, occupation or any other factor, such as income for example, is the deciding factor in these differences.

In general, singles with children are the least satisfied with their indoor living situations, while families with two parents tend to be the most satisfied. The most satisfied group are home-owners. Again, the reason might not simply be the ownership of real estate per se because the variables are not independent, as shown in Figure 2. It can be assumed, moreover, that home-owners tend to be older and have a higher income, which might also influence the results. Last but not least, it was found that rural occupants tend to be more satisfied than urban ones.

\section{Relationships between the constructs}

It seems self-evident that the perceived relevance of different criteria must be correlated in some way with the perceived magnitude of deficiencies in housing stock, as well as with reported occupant satisfaction. We found it therefore necessary to derive hypothetical relationships between them, which could then be validated by a correlation analysis to prove the consistency of their correlation. For the investigation of these relationships, the criteria of 'relevance', 
'perceived deficiency' and 'acceptance' were grouped and set into relation with one another as shown in Figure 8.

\subsection{Hypothetical explanatory model}

Festinger's (1957) theory of cognitive dissonance assumes that all individuals seek cognitive consistence by reducing contradictory thoughts and emotions, so as to bring them into harmony (Kroeber-Riel et al., 2003). Based on this theory, it can be deduced that the relevance and acceptance of a criterion should be consistent. It can be presumed, furthermore, that when someone gives more weight to a criterion he or she is then led to have a lower acceptance of it and vice versa. This is articulated in hypothesis 1 :

H1- There is a negative correlation between the subjective relevance and the degree of acceptance of a given deficiency.

This study also measures the subjectively perceived inconvenience caused to an inhabitant by a deficiency in building stock. One can assume that a higher personal relevance of any given factor, when faced with an actual deficiency will result in a greater subjective assessment of deficiency. Nevertheless, it is assumed that there is a correlation between the perceived deficiency and the constructs of relevance and acceptance, which we phrase thus:
$\mathrm{H} 2+\quad$ There is a positive correlation between the subjective relevance of a criterion and a perceived deficiency thereof.

There is also the possibility that a high level of perceived deficiency leads to a greater weighting of it. Thus, it is impossible to establish the ultimate cause. Since interference cannot be proven, it is assumed to exist for the purposes of this paper. Further investigations should compare the criteria identified here with actual conditions in the residential environment.

Hypothesis 1 assumes a strong correlation between the relevance of criteria and the acceptance of deficiencies. This also implies a relation to perceived deficiencies. It can be assumed that the causality cannot be deduced ex ante because of the possibility of both a positive as well as a negative correlation. A negative correlation would mean that there is a significant perceived deficiency with a low level of acceptance. Individuals judge their conditions more critically if they accept a deficiency less. Alternatively, a positive correlation can be supposed if individuals feel strongly impaired by deficiencies in their living conditions and yet accept them, for example because they are compensated by other criteria. This point can be explained by the fact that all participants are located in their present living situation, which makes them try to live with some of these deficiencies. Also at this juncture, the actual existence of a deficiency can only be assumed, and thus a

\begin{tabular}{|c|c|c|c|}
\hline & Relevance of criteria & Acceptance of deficiencies & Perceived deficiencies \\
\hline 1 & Thermal comfort & $\begin{array}{c}\text { Draught, cold walls } \\
\text { Overheating in summer } \\
\text { Cold room temperature }\end{array}$ & $\begin{array}{l}\text { Draught, cold walls } \\
\text { Overheating in Summer }\end{array}$ \\
\hline 2 & Air quality & $\begin{array}{l}\text { Mould, moist wall } \\
\text { Strong smell }\end{array}$ & Mould, moist wall \\
\hline 3 & Acoustic comfort & $\begin{array}{c}\text { Neighbour noise } \\
\text { Outdoor noise } \\
\text { Technical equipment noise }\end{array}$ & Noise (traffic, neighbours) \\
\hline 4 & Visual comfort & $\begin{array}{l}\text { Poor natural light } \\
\text { Solar glare }\end{array}$ & Poor natural light, solar glare \\
\hline 5 & Room layout & $\begin{array}{l}\text { Little storage space } \\
\text { Poor room layout }\end{array}$ & $\begin{array}{l}\text { Little storage space, poor room } \\
\text { layout }\end{array}$ \\
\hline 6 & Energy use & High heating costs & High energy costs \\
\hline 7 & Influence on indoor climate & $\begin{array}{c}\text { Indoor climate not controllable } \\
\text { Unintelligible technical equipment }\end{array}$ & Indoor climate not controllable \\
\hline 8 & Fire protection & $\begin{array}{l}\text { Only one escape route } \\
\text { Poor fire protection }\end{array}$ & Fire protection deficiency \\
\hline 9 & Health and environment & $\begin{array}{l}\text { Contaminated building components } \\
\text { Electromagnetic pollution }\end{array}$ & Pollutant load \\
\hline 10 & Vibration protection & Vibrations & Vibrations \\
\hline 11 & Accessibility & Barriers & Barriers \\
\hline
\end{tabular}

Fig. 8. Theoretical relation of the criteria. 


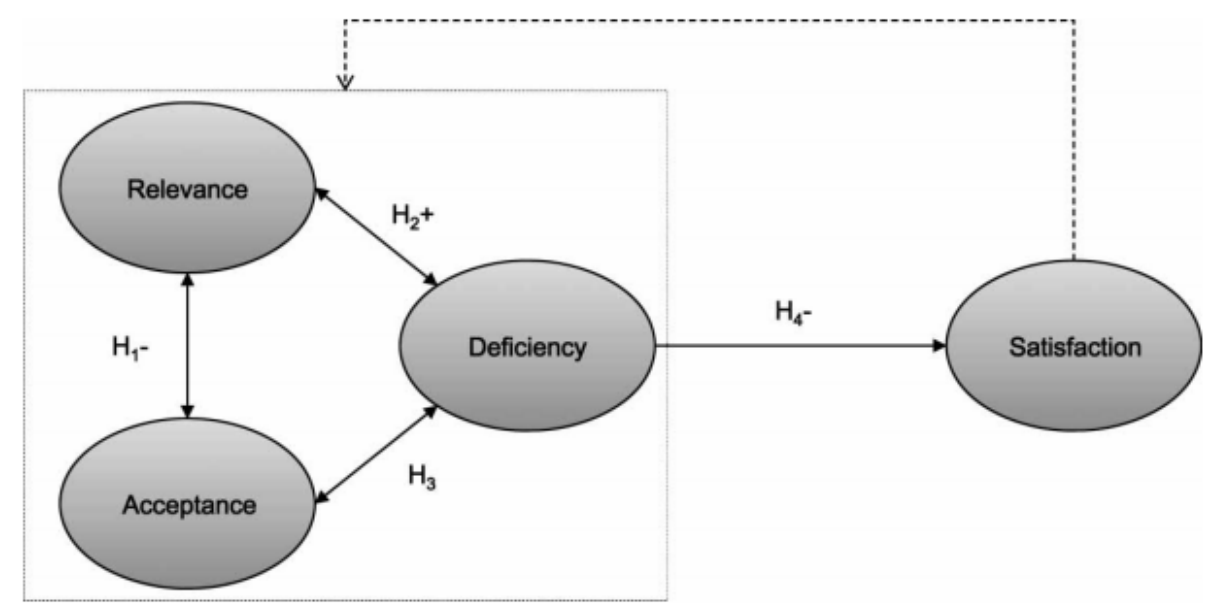

Fig. 9. Hypothetical model of the relationships.

hypothetical coherence must be phrased generally:

H3 There is a correlation between the acceptance of deficiencies and the perceived harm thereof.

Finally, the model includes one more item that we must consider, namely the occupant's total satisfaction with his or her living situation. Because the level subjective perceived deficiency of a specific criterion quasi expresses the dissatisfaction with it, a causal correlation between them can be assumed (Flade, 2006). We assume that the total amount of perceived deficiencies affects the total level of satisfaction that occupants have with their dwellings:

H4- There is a negative correlation between a perceived deficiency and total satisfaction.

Only in the case of this correlation can a tendency be assumed. This, however, does not exclude the possibility of feedback mechanisms between total satisfaction and the relevance of individual criteria on the one hand or the acceptance of deficiencies on the other.

\subsection{Review of the correlations}

The relationships between the three constructs of relevance of criteria, acceptance and perception of deficiencies are validated through a correlation analysis. A linear relation between each two metric variables is assumed (Kuß, 2004) and we therefore apply the calculation of Pearson's correlation coefficient for our analysis:

$$
r=\frac{\sum_{i=1}^{n}\left(x_{i}-\bar{x}\right)\left(y_{i}-\bar{y}\right)}{\sqrt{\sum_{i=1}^{n}\left(x_{i}-\bar{x}\right)^{2} \cdot\left(y_{i}-\bar{y}\right)^{2}}}
$$

The correlation coefficient $r$ can take values between 1 and +1 , where $r=-1$ means an absolute negative correlation with linear dependence, where $r=0$ means absolute independence and where $r=+1$ implies an absolute positive correlation with linear dependence.

Altogether, the survey recorded subjective views with regard to 11 criteria. Because some questions referred to several criteria simultaneously, they had to be aggregated by averaging. Thus each question (relevance, acceptance, deficiency) always contained 11 separate variables. These criteria were compared using contingency tables using the SPSS 17.0 computer program. This allowed correlations between secondary criteria to be revealed. For instance, the relevance of the criterion influence on indoor climate correlates with the acceptance for thermal comfort. However, only the focused correlations among the related criteria are outlined and analysed in the following, for reasons of complexity reduction (Table 1 ).

The overview includes the correlation coefficient (r) for the criteria together with the respective significance level (p) for all three hypothetical correlations. The significance level of a correlation provides for the possibility of generalizing the results. Thus, the correlation must be accepted with a confidence level of $99 \%$, if $p=0.01$. According to Gossauer et al. (2007), P-values less than 0.05 are significant in Post Occupancy Evaluations.

On the other hand, the correlation coefficient implies the strength of the correlations, with the result that a correlation $r$ close to 1 is very strong. The correlation coefficients of all 11 criteria imply that there is a negative correlation between relevance and acceptance. Thus, hypothesis 1 can be verified with a confidence level of $99.9 \%$. The strength of the correlation varies depending on the criterion. This, on the one hand implies how strongly the constructs depend on each other, and on the other conveys a better impression of the possibility of generalizing the results with regard to those aspects with a low significance level. 
Table 1. Correlations between the constructs

\begin{tabular}{|c|c|c|c|}
\hline & $\begin{array}{c}\text { Relevance \& } \\
\text { Acceptance } \\
\text { (H1) }\end{array}$ & $\begin{array}{c}\text { Relevance \& } \\
\text { Deficiency } \\
\text { (H2) }\end{array}$ & $\begin{array}{c}\text { Deficiency \& } \\
\text { Acceptance } \\
\text { (H3) }\end{array}$ \\
\hline Criteria & $\mathbf{r}$ & $\mathbf{r}$ & $\mathbf{r}$ \\
\hline Thermal comfort & $-0,282^{* *}$ & $-0,003$ & 0,038 \\
\hline Air quality & $-0,295^{* *}$ & $-0,044$ & $0,161^{* *}$ \\
\hline Acoustic comfort & $-0,464^{* *}$ & $0,123^{* *}$ & $-0,066^{*}$ \\
\hline Visual comfort & $-0,308^{* *}$ & $0,054^{*}$ & $0,090^{* *}$ \\
\hline Room layout & $-0,312^{* *}$ & $-0,010$ & 0,027 \\
\hline Influence on climate & $-0,356^{* *}$ & $0,082^{* *}$ & $0,086^{* *}$ \\
\hline Energy use & $-0,191^{* *}$ & $0,085^{* *}$ & $-0,007$ \\
\hline Fire protection & $-0,596^{* *}$ & $0,277^{* *}$ & $-0,265^{* *}$ \\
\hline Health \& environment & $-0,495^{* *}$ & $0,129^{* *}$ & $-0,011$ \\
\hline Vibration protection & $-0,389 * *$ & $0,160^{* *}$ & $0,067^{*}$ \\
\hline Accessibility & $-0,570^{* *}$ & $0,305^{* *}$ & $-0,275^{* *}$ \\
\hline
\end{tabular}

Looking at the correlation data of the constructs of relevance and perceived deficiencies, it becomes clear that not all criteria exhibit significant correlations. This is possibly due to missing variation in responses. For instance, the descriptive analysis shows that there exist hardly any deficiencies that link thermal comfort and room layout (Average: 3 and 4; Std.-dev. 0.8 and 0.9 ). However, it is obvious that in 8 out of 11 criteria there is a significant positive correlation between the constructs, with the result that hypothesis 2 can also be seen as confirmed.

For validation of the third hypothesis, the correlation data of the constructs of deficiency and acceptance take centrestage. We assumed that a correlation could be either positive or negative, because both can be deduced logically. Table 1 shows that both positive and negative correlation coefficients were calculated, but that in only 7 out of 11 criteria could a significant correlation be proven. Because this affects the majority of the criteria, hypothesis 3 can also be taken as verified.

Further, we consider the respective criteria with regard to positive and negative correlations. With positive correlations it can be assumed that occupants are able to tolerate deficiencies. When there is significant deficiency, other criteria are only accepted with difficulty. When these deficiencies are very pronounced, we assume that further negative occurrences will follow, which will result in complaints (to a landlord, for example) or even in tenants moving out (Flade, 2006; Walden, 2004). Finally, this analysis shows how the relevance of individual items is affected by perceived deficiencies, and thus gives first indications concerning the hypothesis that the significance of a criterion can develop during a tenancy. This means that tolerance levels not pre-formed for all individuals (or target groups) before they move in to a dwelling. Based on this model, future research could put the resulting relationship between behaviour and intention into focus.

\subsection{Determinants of satisfaction}

Whereas the first part of the model was tested using a correlation analysis, we validated hypothesis 4 using a regression analysis. The verification of causal relationships was calculated using a linear stepwise regression in which the significance-level was set to 0.1 for the exclusion of independent variables and to 0.05 as a criterion for inclusion. Total satisfaction is a dependent variable, while the perceived deficiency of the various living situation criteria are shown as independent variables. A regression model which evaluated all target groups verified the proposed general correlation between deficiency and satisfaction. A multi-collinearity test was conducted to make sure that the independent variables did not correlate among each other. As no high VIF-value (near 10 ) was found (all VIF-values of the model are $<2$ ), no variable needed to be excluded from the model. The results of the regression analysis for all target groups are listed in Table 2 .

The model suggests that most of the criteria have an influence on total satisfaction. $25 \%$ of the variance in the dependent variable can be explained by all included variables $(\mathrm{R} 2=0.255)$. Finally, there are seven criteria which have a negative influence (with a $99 \%$ probability) on total occupant satisfaction with their living situations, thus proving hypothesis 4 .

The variables of vibrations, high energy costs, pollutants and poor fire protection were excluded because they have no significant impact on total satisfaction in this study. Along these lines, it is particularly interesting that occupants claim 
energy and heating costs to be very important criteria, but in they turn out to be immaterial as far as total satisfaction is concerned. This could be traced back to the fact that people simply accept certain costs over which they have no control.

According to the results, the model can show negative as well as positive evaluations of residential quality. When deficiencies are slight, the total satisfaction is indeed higher.
Furthermore, it was proved empirically that satisfaction does not only depend on the perception of deficiency, but also on the relevance that individuals attribute to a given criterion. Finally, by statistically analysing the relative relevance of living criteria from the occupant's point of view, this study revealed data that could be relevant for both further research and practise.

Table 2. Results of the regression analysis

\begin{tabular}{|c|c|c|c|c|c|}
\hline \multirow{2}{*}{$R^{2}=0,255$ corr. $R^{2}=0,251$} & \multicolumn{2}{|c|}{ Not standardized coefficients } & \multirow{2}{*}{$\begin{array}{c}\text { Standardized } \\
\text { coefficients } \\
\text { Beta }\end{array}$} & \multirow{2}{*}{$\mathbf{T}$} & \multirow{2}{*}{ Sig. } \\
\hline & B & $\begin{array}{c}\text { Standard } \\
\text { error }\end{array}$ & & & \\
\hline (constant) & 0,002 & 0,023 & & 0,087 & 0,931 \\
\hline Noise (traffic , neighbours), ... & $-0,245$ & 0,025 & $-0,244$ & $-9,758$ & 0,000 \\
\hline Indoor climate not controllable, ... & $-0,161$ & 0,029 & $-0,159$ & $-5,491$ & 0,000 \\
\hline Little storage space, ... & $-0,128$ & 0,024 & $-0,129$ & $-5,260$ & 0,000 \\
\hline Poor natural light, solar glare, ... & $-0,127$ & 0,027 & $-0,126$ & $-4,733$ & 0,000 \\
\hline Draught, cold walls, ... & $-0,128$ & 0,036 & $-0,100$ & $-3,553$ & 0,000 \\
\hline Barriers, ... & 0,095 & 0,025 & 0,094 & 3,735 & 0,000 \\
\hline Mould, moist wall, ... & $-0,072$ & 0,026 & $-0,071$ & $-2,756$ & 0,006 \\
\hline
\end{tabular}

\section{Summary}

Until now, occupant-requirement surveys have almost exclusively been conducted for office buildings. Representative studies concerned with the needs of occupants of residential buildings are very uncommon. To improve the literature, a preliminary study took into account human needs and already existing certification systems to identify 11 useroriented criteria. The parameters of relevance, acceptance and deficiency were probed in the context of a Post Occupancy Evaluation (POE) of 1,416 occupants. The high level of representativeness of the sample was confirmed by a comparison with the general German population.

On the basis of the ascertained data, a ranking from the viewpoint of the occupants was deduced, based on the subjective relevance of the respective criteria. Physical needs such as air quality and thermal comfort closely followed by energy use took the places of highest relevance. The analysis of the acceptance rates of different deficiencies showed that health-endangering problems like mould or contaminated building materials are almost universally considered unacceptable. High heating costs came in third. The perceived deficiency of high energy costs, noise and problems with thermal comfort (draught, cold walls, etc.) were ranked highest. Understanding this ranking has relevance in potentially supporting a broad range of real estate-associated decision-making processes.

Occupants were also asked about their satisfaction with their current living conditions. It was found that $70 \%$ were satisfied to very satisfied and only $9 \%$ could be classified as unsatisfied or very unsatisfied. However, satisfaction levels do vary among target groups.

Beyond this, the study statistically analysed the way in which constructs of relevance, acceptance, deficiency and satisfaction interact. A model explaining these interactions was created, and, based on the gathered data, was successfully validated through correlation and regression analyses. The essential aspects of this model are:

(1) There is a negative correlation between the subjective relevance and the degree of acceptance of a given deficiency.

(2) There is a positive correlation between the subjective relevance of a criterion and a perceived deficiency thereof.

(3) There is a correlation between the acceptance of deficiencies and the perceived harm thereof.

(4) There is a negative correlation between a perceived deficiency and total satisfaction.

The correlations between relevance, acceptance, deficiency and satisfaction are very useful for the business of real estate. The results could provide advice to decision makers (designers, architects, landlords etc.) on how to maximise the satisfaction of building occupants. Additionally, we were able to prove that the relevance of individual criteria also correlates with current deficiencies and is not only predetermined. This means, for example, that a designer should also attend to less important criteria which could be perceived as deficient, and could then over time gain relevance in the eyes of occupants. Furthermore, the results of this study offer 
a tool for reviewing the methods by which criteria are selected and weighted in existing building assessment tools.

These new findings provide orientation for further study. For example, future research should investigate how far subjective deficiencies correspond with actual ones. While our study sheds light on the role of occupants' subjective perceptions, it would be interesting to confirm these results with objective measures of actual living conditions, for example in terms of air quality or thermal comfort.

Additionally, the effect of potential feedback mechanisms between levels of occupant satisfaction and the influencing criteria should be investigated. Finally, future research should address how objective living conditions, interacting with occupants' perceptions leads to changes in occupant behavior.

\section{Acknowledgements}

This publication is a product of the 'methods and building material for user-oriented restoration of buildings' project, which is sponsored by the Federal Ministry of Education and Research (BMBF). Many thanks to Judith Muenster, Sandra Bergelt, Jacqueline Frey, Carolin Koeppe and Sabrina Lindner. Thanks also to Weimarer Wohnstaette, OBI Weimar-Suessenborn and to the German Energy Agency (DENA) for supporting us to conduct the survey.

\section{References}

Bergelt, S., Frey, J., Köhlmann, S., Köppe, C., \& Lindner, S. (2010). Kriterien der nutzerorientierten Bausanierung II. Thesis, Bauhaus-Universität Weimar.

Bischof, W., Bullinger Naber, M., Kruppa, B., Müller, B. H., \& Schwab, R. (2003). Expositionen und gesundheitliche Beeinträchtigungen in Bürogebäuden: Fraunhofer IRB Verlag, Stuttgart.

Cao, B., Ouyang, Q., Zhu, Y., Huang, L., Hu, H., \& Deng, G. (2012). Development of a multivariate regression model for overall satisfaction in public buildings based on field studies in Beijing and Shanghai. Building and Environment, 47(1), 394399.

Choi, J., Aziz, A., \& Loftness, V. (2010). Investigation on the impacts of different genders and ages on satisfaction with thermal environments in office buildings. Building and Environment, 45(6), 1529-1535.

Choi, J. H., Loftness, V., \& Aziz, A. (2012). Postoccupancy evaluation of 20 office buildings as basis for future IEQ standards and guidelines. Energy and Buildings, 46, 167175 .

Festinger, L. (1957). A theory of cognitive dissonance: Stanford University Press.
Flade, A. (2006). Wohnen psychologisch betrachtet. Bern: Verlag Hans Huber.

Frontczak, M., Andersen, R. V., \& Wargocki, P. (2012a). Questionnaire survey on factors influencing comfort with indoor environmental quality in Danish housing. Building and Environment, 50, 56-64.

Frontczak, M., Schiavon, S., Goins, J., Arens, E., Zhang, H., \& Wargocki, P. (2012b). Quantitative relationships between occupant satisfaction and satisfaction aspects of indoor environmental quality and building design. Indoor Air, 22(2), 119-131.

German Federal Statistical Office. (2008). Datenreport.

German Federal Statistical Office. (2009a).

Deutschland - Land und Leute.

German Federal Statistical Office. (2009b). Statistisches Jahrbuch.

Gossauer, E. (2008). Nutzerzufriedenheit in Bürogebäuden - eine Feldstudie. $\mathrm{PhD}$ thesis, Universität Karlsruhe.

Gossauer, E., \& Wagner, A. (2007). Post-occupancy Evaluation and Thermal Comfort: State of the Art and New Approaches. Advances in Building Energy Research, 1(1), 151175.

Haghighat, F., \& Donnini, G. (1999). Impact of psychosocial factors on perception of the indoor air environment studies in 12 office buildings. Building and Environment, 34(4), 479-503.

Hellwig, R. T. (2005). Thermische Behaglichkeit. Dissertation PhD-thesis, Technische Universität München.

Hummelgaard, J., Juhl, P., Sæbjörnsson, K. O., Clausen, G., Toftum, J., \& Langkilde, G. (2007). Indoor air quality and occupant satisfaction in five mechanically and four naturally ventilated open-plan office buildings. Building and Environment, 42(12), 4051-4058.

Humphreys, M. A. (2005). Quantifying occupant comfort: Are combined indices of the indoor environment practicable? Building Research and Information, 33(4), 317325.

Kim, J., \& de Dear, R. (2012). Nonlinear relationships between individual IEQ factors and overall workspace satisfaction. Building and Environment, 49(1), 33-40.

Kroeber-Riel, W., \& Weinberg, P. (2003). Konsumentenverhalten. München: Vahlen.

Kühn, K. (2008). Nutzerzufriedenheit. In M. Hegger (Ed.), elife - Lebenszyklusbetrachtung und Optimierung von Instandsetzungsprozessen im Wohnungsbau (Vol. Bauforschung fuer die Praxis 86, pp. 155-188): Fraunhofer IRB Verlag.

Kuß, A. (2004). Marktforschung. Grundlagen der Datenerhebung und Datenanalyse. Wiesbaden Gabler.

Kwon, S. H., Chun, C., \& Kwak, R. Y. (2011). Relationship between quality of building maintenance management services for indoor environmental quality and occupant satisfaction. Building and Environment, 46(11), 2179-2185.

Lai, A. C. K., Mui, K. W., Wong, L. T., \& Law, L. Y. (2009a). An evaluation model for indoor environmental quality (IEQ) 
acceptance in residential buildings. Energy and Buildings, 41(9), 930-936.

Lai, J. H. K., \& Yik, F. W. H. (2009b). Perception of importance and performance of the indoor environmental quality of high-rise residential buildings. Building and Environment, 44(2), 352-360.

Meir, I. A., Garb, Y., Jiao, D., \& Cicelsky, A. (2009). Postoccupancy evaluation: An inevitable step toward sustainability. Advances in Building Energy Research, 3(1), 189220.

Muhic, S., \& Butala, V. (2004). The influence of indoor environment in office buildings on their occupants: Expectedunexpected. Building and Environment, 39(3), 289-296.

Münster, J. (2009). Kriterien der nutzerorientierten Bausanierung. Bachelorarbeit Thesis, Bauhaus-Universität Weimar.

Paul, W. L., \& Taylor, P. A. (2008). A comparison of occupant comfort and satisfaction between a green building and a conventional building. Building and Environment, 43(11), 1858-1870.

Prechtl, C., Rabe, S., Röther, U., \& Werner, T. (2007). Interdisziplinäre nutzerorientierte nachhaltige Optimierung von Stoff- und Energieströmen im Gebäude (INNOSEG). Final report

Schakib-Ekbatan, K., Wagner, A., \& Lussac, C. (2010). Occupant satisfaction as an indicator for the socio-cultural dimension of sustainable office buildings - Development of an overall building index. Paper presented at the Adapting to Change: New Thinking on Comfort, Cumberland Lodge, Windsor, UK, 9-11 April

Voelker, C., Beckmann, J., \& Kornadt, O. (2011). Results from a large scale study on user requirements for residential buildings [Ergebnisse einer Großstudie über Nutzeranforderungen an Wohngebäude]. Bauphysik, 33(3), 167-176.

Wagner, A., Gossauer, E., Moosmann, C., Gropp, T., \& Leonhart, R. (2007). Thermal comfort and workplace occupant satisfaction-Results of field studies in German low energy office buildings. Energy and Buildings, 39(7), 758-769.

Wagner, A., Mossmann, C., Gropp, T., Gossauer, E., \& Farghal, A. A. (2008). Thermische Komfort in einem natürlich gelüfteten Gebäude - Ergebnisse einer Felduntersuchung. $g i$ Gesundheitsingenieur, 129(5), 233-239.

Walden, R. (2004). Wohnzufriedenheit, Wohlbefinden und Wohnqualität Psychologie und gebaute Umwelt (pp. 75113): Institut Wohnen und Umwelt, Darmstadt.

Wong, L. T., Mui, K. W., \& Hui, P. S. (2007). A multivariate-logistic model for acceptance of indoor environmental quality (IEQ) in offices. Building and Environment, 43(1), 1-6.

Zagreus, L., Huizenga, C., Arens, E., \& Lehrer, D. (2004). Listening to the occupants: a Web-based indoor environmental quality survey. Indoor Air, 14, 65-74. doi: 10.1111/j.16000668.2004.00301.x

Zhang, Y., \& Altan, H. (2011). A comparison of the occupant comfort in a conventional high-rise office block and a contemporary environmentally-concerned building. Building and Environment, 46(2), 535-545. 